\title{
Compound Optical Film Using Gray Scale Mask Embedded with Microvoids
}

\author{
C. T. Pan, ${ }^{1,2}$ Y. C. Chen, ${ }^{1}$ Y. J. Chen, ${ }^{1}$ W. C. Wang, ${ }^{1}$ H. C. Yang, ${ }^{1}$ and H. C. Wu ${ }^{1}$ \\ ${ }^{1}$ Department of Mechanical and Electro-Mechanical Engineering, National Sun Yat-Sen University, Kaohsiung 80424, Taiwan \\ ${ }^{2}$ National Science Council Core Facilities Laboratory for Nano-Science and Nano-Technology in Kaohsiung-Pingtung Area, \\ Center for Nanoscience and Nanotechnology, National Sun Yat-Sen University, Kaohsiung 80424, Taiwan
}

Correspondence should be addressed to C. T. Pan, panct@faculty.nsysu.edu.tw

Received 15 July 2012; Accepted 11 September 2012

Academic Editor: Edvard Kokanyan

Copyright () 2012 C. T. Pan et al. This is an open access article distributed under the Creative Commons Attribution License, which permits unrestricted use, distribution, and reproduction in any medium, provided the original work is properly cited.

This study presents a compound optical film to improve luminance and uniformity to apply in side-LED (light-emitting diode) backlight module. LIGA (lithographie galvanoformung abformung) technology, soft lithography, and homemade gray scale mask were combined to fabricate microlens array. Optical film with variable size microlens array embedded with microvoids was designed and manufactured. FRED software was used to simulate optical performance. Microvoids were quantitatively embedded in the PDMS (polydimethylsiloxane) optical film. Under the quantitative control of air pressure, those microvoids inside the optical film can cause light diffusion. The compound optical film with embedded microvoids, multiaspect ratio, and variable size microlens array can be fabricated quickly without substrate. Luminance colorimeter BM-7A from TOPCON was used to carry out the optical measurement. According to the measured data, the compound optical film with embedded microvoids can enhance the luminance up to $5 \%$ and the uniformity up to $6.5 \% \sim 8.4 \%$. The optical efficiency can be improved via the compound optical film.

\section{Introduction}

A light-emitting diode (LED) is a semiconductor light source. LEDs are used in many devices and are increasingly used for other lighting. LEDs show many advantages such as high brightness, smaller size, fast switching, improved robustness, low energy consumption, and long lifetime. Lamp-LED and side-LED are emitting-light types for LED backlight of liquid crystal display (LCD). Side-LED has advantages: less LEDs usage than lamp-LED, and side-LED is normally used for small size panel. A compound optical film is combined with light guide plate, diffusion sheet, and brightness enhancement film to enhance optical effect. How to improve weakness such as poor uniformity, the multilayer film structures, and the complex manufacturing process of the side-LED backlight module is a crucial issue.

Many researches presented geometrical design to improve optical characteristics. A solar collecting optical film with horizontal cylinder microlens array (HCMA) can reduce the effect of reflection as light arrives at the surface and therefore can increase the refraction coefficient [1]. Batch fabrication of an eyeball-like spherical microlens array (ESMA) not only can reduce microassembly cost, but also can replace conventional ball lenses or costly gradient refractive index without sacrificing performance. The ESMA is an eyeball-like spherical lens which can focus light in all directions, thus providing application flexibility for optical purposes [2]. A new packaging method for LEDs with a gapless dual-curvature microlens array (GDMLA) was used to improve its ability to illuminate a panel. The fabricated GDMLA had the characteristics of dual curvatures and a high fill-factor of $100 \%$, and the results demonstrated that the GDMLA is a good optical device for use in LED packages [3]. A UV (ultraviolet) curable polymer was used as the material of an optical film in this replication process of a microlens array with high fill-factor to enhance brightness and scatter [4]. Some researches also used aspheric geometrical structure design to improve the optical characteristics. A new fabrication process with UV laser direct writing method was developed to embed microstructures inside the glass. 


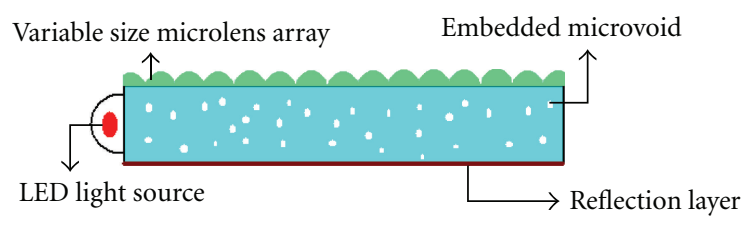

Figure 1: Design of optical film.

The optical properties of glass such as reflection and refraction indexes can be modified [5]. A modified hot-embossing process fabricated microtriangular-pyramidal array and the optical film of PMMA with microtriangular-pyramidal array were packaged on LED to improve its lighting uniformity and luminance [6]. An optical film with aspherical microlens array by using multistep lithography process for an OLED (organic light-emitting diode) package was fabricated, by which method the luminance of OLEDs can be enhanced [7]. By adjusting the heating temperature and the sealed air volume, the convex microlens shape was produced in the photoresist that was compressed by the thermal expansion of sealed air to form a semispherical shell [8]. A simple and novel method was used to fabricate nonspherical SU-8 microlens array utilizing a soft SU-8 stamping approach and an electrostatic pulling process [9]. Gray-scale technology has been applied in arbitrary $3 \mathrm{D}$ microstructures in various materials. Photolithography using grayscale masks provides a much higher throughput than direct-write methods. In addition, it is also capable of fabricating structures with a much higher vertical precision than multiple-step photolithography $[10,11]$.

The study presents a new compound optical film to improve luminance and uniformity to apply in side-LED backlight module. The microlens array was fabricated by using LIGA (lithographie galvanoformung abformung), technology, soft lithography, and homemade gray scale mask. This compound optical film with microlens array was designed optically so that this compound optical film is better in respect of luminance and uniformity. An embeddedvoids optical film of variable size microlens array is designed and manufactured. This optical film with embedded microvoids, multiaspect ratio, and variable size microlens array can be fabricated quickly without substrate. The optical film can enhance the luminance and uniformity.

\section{Design}

In the study, a new compound optical film was designed, and it integrates the functions of the light guide plate, brightness enhancement film, and reflection layer all together. Light is guided to the emission surface by diffusion and guide structure. The design of compound optical film includes variable size microlens array, embedded microvoids, reflection layer, and light source, as shown in Figure 1. The results of UV/VIS spectrophotometer show that the transmittance of PDMS (polydimethylsiloxane) can be obtained up to $90 \%$ for the wavelength from $390 \mathrm{~nm}$ to $780 \mathrm{~nm}$, as shown in Figure 2. Therefore, PDMS polymer was used as film material to embed microvoids as diffusion and light guide structure.

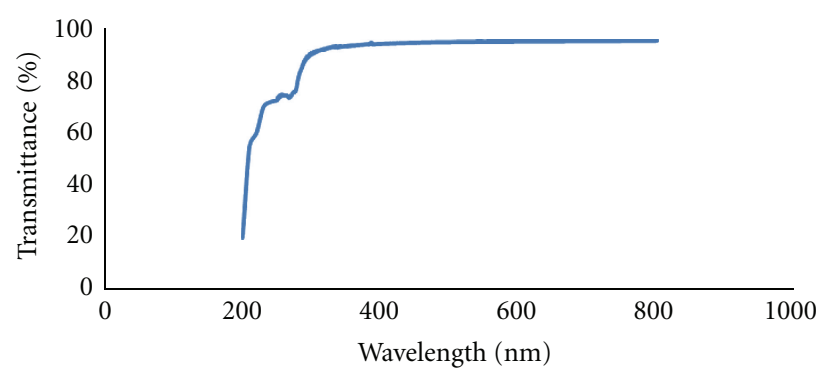

FIgURE 2: The curve diagram of PDMS transmittance.

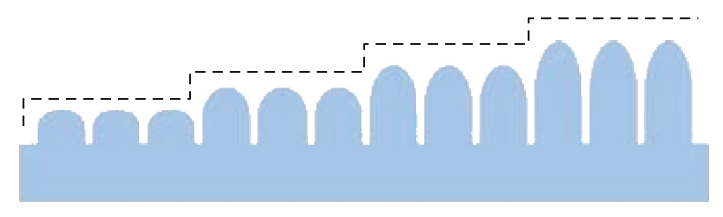

Low aspect ratio $\langle\ldots \ldots \ldots \ldots \ldots \ldots \ldots \ldots \ldots \ldots \ldots$, High aspect ratio

FIgURE 3: Gray scale microlens array.

TABLE 1: Parameters of gray scale microlens array.

\begin{tabular}{lcc}
\hline No. & Diameter & $\begin{array}{c}\text { Height of microlens array } \\
\text { (the order is from close to far of the light } \\
\text { source) }\end{array}$ \\
\hline $\mathrm{D} 20-\mathrm{A}$ & $\mathrm{D}=20 \mu \mathrm{m}$ & $5 \mu \mathrm{m}, 15 \mu \mathrm{m}, 25 \mu \mathrm{m}, 35 \mu \mathrm{m}$ \\
$\mathrm{D} 20-\mathrm{B}$ & $\mathrm{D}=20 \mu \mathrm{m}$ & $35 \mu \mathrm{m}, 25 \mu \mathrm{m}, 15 \mu \mathrm{m}, 5 \mu \mathrm{m}$ \\
$\mathrm{D} 40-\mathrm{A}$ & $\mathrm{D}=40 \mu \mathrm{m}$ & $5 \mu \mathrm{m}, 15 \mu \mathrm{m}, 25 \mu \mathrm{m}, 35 \mu \mathrm{m}$ \\
$\mathrm{D} 40-\mathrm{B}$ & $\mathrm{D}=40 \mu \mathrm{m}$ & $35 \mu \mathrm{m}, 25 \mu \mathrm{m}, 15 \mu \mathrm{m}, 5 \mu \mathrm{m}$ \\
\hline
\end{tabular}

The gray scale microlens array was designed and simulated by commercial optical software, FRED. Figure 3 shows the illustration of the gray scale microlens array, and Table 1 shows the parameters of the design of the gray scale microlens array. Two different diameters of $20 \mu \mathrm{m}$ and $40 \mu \mathrm{m}$, and four different heights of microlens array of $5 \mu \mathrm{m}, 15 \mu \mathrm{m}$, $25 \mu \mathrm{m}$, and $35 \mu \mathrm{m}$, were selected. A gap between adjacent two microlens is $70 \mu \mathrm{m}$.

In FRED optical simulation, the result shows that when optical film is embedded voids in the structure, no extra diffuser film is needed. The simulated result of luminance distribution of the analysis layer is shown in Figure 4. The result without lens shows that most light intensity focuses on the film close to the light source-the average luminance is calculated as $48.5\left(\mathrm{~cd} / \mathrm{m}^{2}\right)$ and the uniformity is $24.4 \%$.

In addition, the optical simulation of vairous sizes of microlens array with embedded micro-void film was carried out. The purpose is to improve the luminance uniformity of backlight module. Figures 5 and 6 show four simulation results of average luminance and the uniformity, as listed in Table 2. D20-B and D40-B have better uniformity than other two cases, so they were adopted as the parameters to produce compound optical films. The determined parameters are shown in Table 3. 


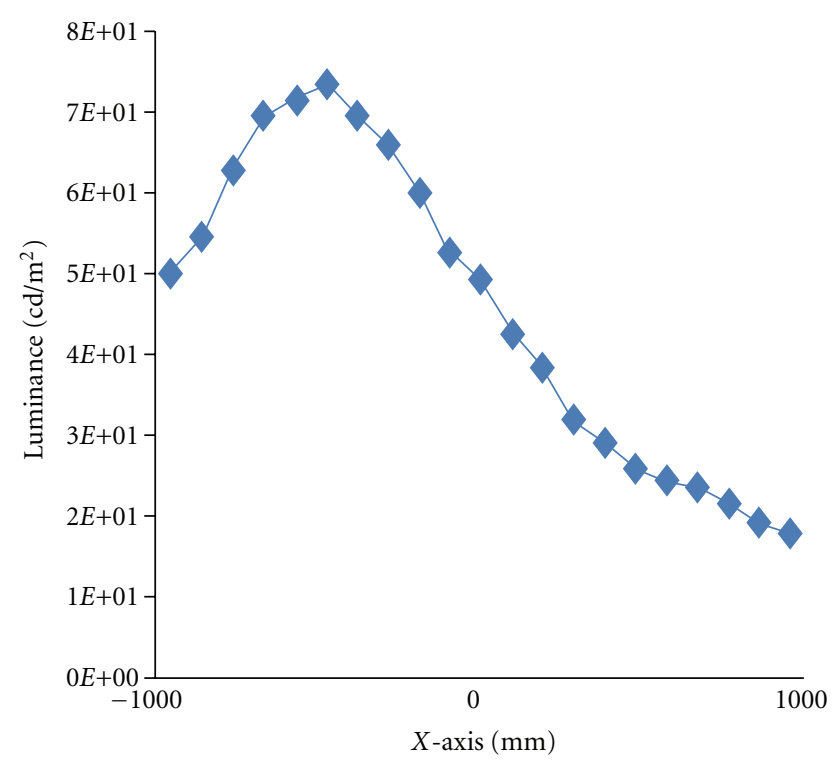

No lens

FIGURE 4: Luminance of embedded voids optical film.

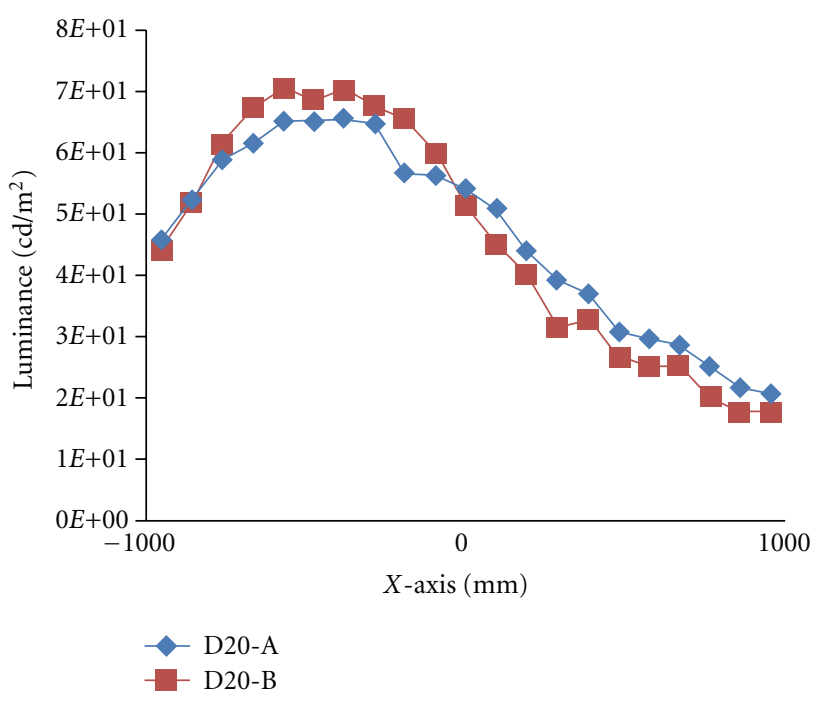

Figure 5: $X$-axis $2 \mathrm{D}$ contour data analysis diagram.

\section{Experiment}

3.1. Gray Scale Microlens Array Mold. A nine gray-scale image was designed to fabricate the mask, as shown in Figure 7. A photography film was defined by a nine-scale gray scale image in computer monitor, as shown in Figure 8. The dimension of the photography film is $2 \mathrm{~cm} \times 2 \mathrm{~cm}$, the image on monitor of $20 \mathrm{~cm} \times 20 \mathrm{~cm}$, the distance between the photography film and the shutter is $4.5 \mathrm{~cm}\left(\mathrm{~L}_{2}\right)$, and the distance between the shutter and the monitor is $45 \mathrm{~cm}\left(\mathrm{~L}_{1}\right)$.

3.2. Measurement of Optical Transmittance and Contour of the Surface. The optical transmittances of each gray scale of the mask were measured by UV/VIS spectrophotometer.

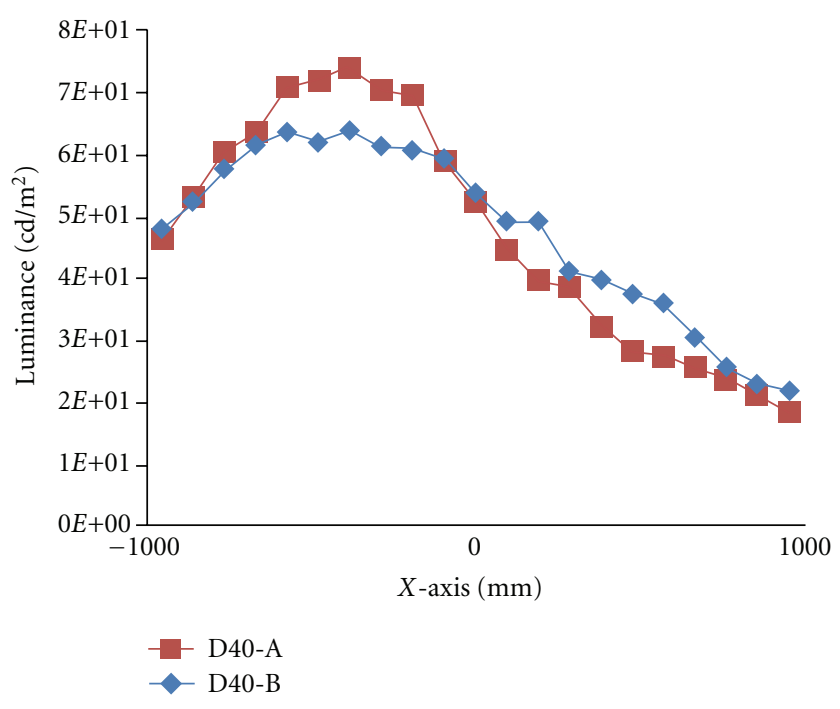

Figure 6: $X$-axis 2D contour data analysis diagram.

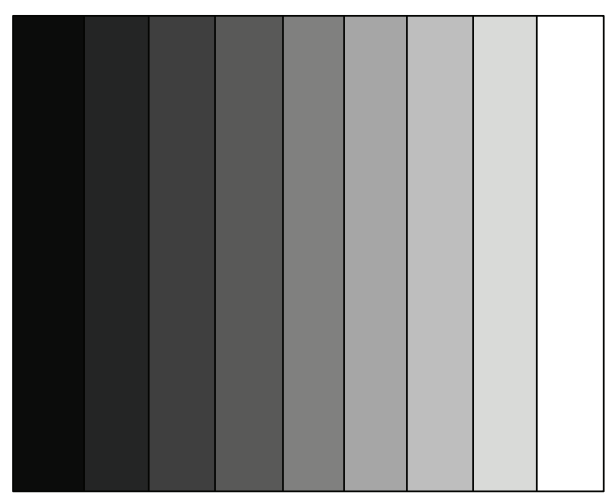

FIgURE 7: Nine-scale gray scale.

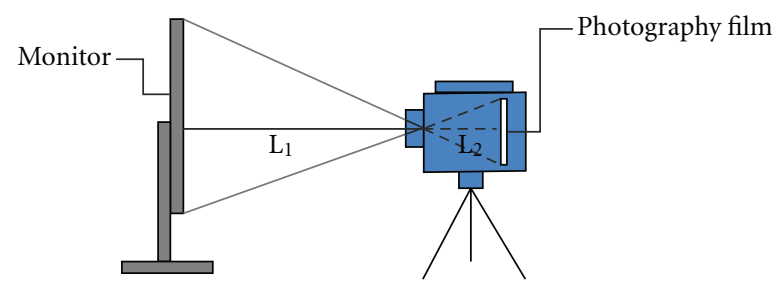

FIGURE 8: Gray scale mask production sketch.

TABLE 2: Gray scale microlens array simulated average luminance and uniformity.

\begin{tabular}{lcc}
\hline No. & Average Luminance $\left(\mathrm{cd} / \mathrm{m}^{2}\right)$ & Uniformity \\
\hline D20-A & 45.8 & $26.1 \%$ \\
D20-B & 46.4 & $31.6 \%$ \\
D40-A & 50.4 & $27.2 \%$ \\
D40-B & 49.7 & $33.4 \%$ \\
\hline
\end{tabular}

The wavelength of UV light source is $365 \mathrm{~nm}$ of I-line. The relationship between the light transmittance at wavelength $365 \mathrm{~nm}$ and the contour of the surface of the gray scale 
TABLE 3: The parameter layouts of gray microlens array optical films.

\begin{tabular}{lcccc}
\hline No. & Height layout $(\mu \mathrm{m})$ & Diameter layout $(\mu \mathrm{m})$ & Average luminance $\left(\mathrm{cd} / \mathrm{m}^{2}\right)$ & Uniformity $(\%)$ \\
\hline No lense & 0 & 0 & 48.5 & 24.4 \\
D40-B & $35,25,15,5$ & 40 & 49.7 & 33.4 \\
D20-B & $35,25,15,5$ & 20 & 46.4 & 31.6 \\
\hline
\end{tabular}

TABLE 4: The relationship between the light transmittance at wavelength $365 \mathrm{~nm}$ and the contour of the surface of the negative of gray scale.

\begin{tabular}{lcc}
\hline Gray scale no. & $\begin{array}{c}\text { Transmittance at wavelength } \\
365 \mathrm{~nm}\end{array}$ & $\begin{array}{c}\text { Height of scale } \\
(\mu \mathrm{m})\end{array}$ \\
\hline 1 & $5.69 \%$ & - \\
2 & $6.91 \%$ & 6.22 \\
3 & $9.28 \%$ & 13.24 \\
4 & $10.52 \%$ & 16.96 \\
5 & $12.16 \%$ & 20.1 \\
6 & $13.83 \%$ & 27.33 \\
7 & $14.91 \%$ & 30.15 \\
8 & $16.02 \%$ & 35.46 \\
9 & $17.56 \%$ & 39.89 \\
\hline
\end{tabular}

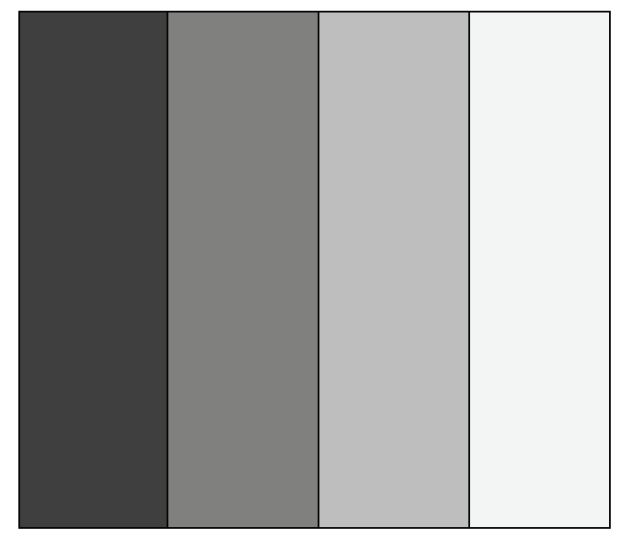

FIgURE 9: Arrangement of gray scale image.

mask is shown in Table 4. Comparing simulation with measurement, no. 2 , no. 3 , no. 6 , and no. 8 are close to the previously designed height, so that the four cases were chosen to fabricate the gray scale mask, and the heights are $6.22 \mu \mathrm{m}$, $13.24 \mu \mathrm{m}, 27.33 \mu \mathrm{m}$, and $35.46 \mu \mathrm{m}$, respectively. The four steps of gray scale image are arranged, as shown in Figure 9, and the homemade gray scale mask is shown in Figure 10.

3.3. Manufacturing Process of the Mold. The mold with multistep microlens array was fabricated. The manufacturing process includes lithography using gray scale mask and electroplating as shown in Figure 11. Negative photoresist, THB-126N, was coated on the glass substrate, as shown in Figure 11(a), and the thickness of photoresist is about $50 \mu \mathrm{m}$. The photoresist was exposed by I-line of $365 \mathrm{~nm}$ in

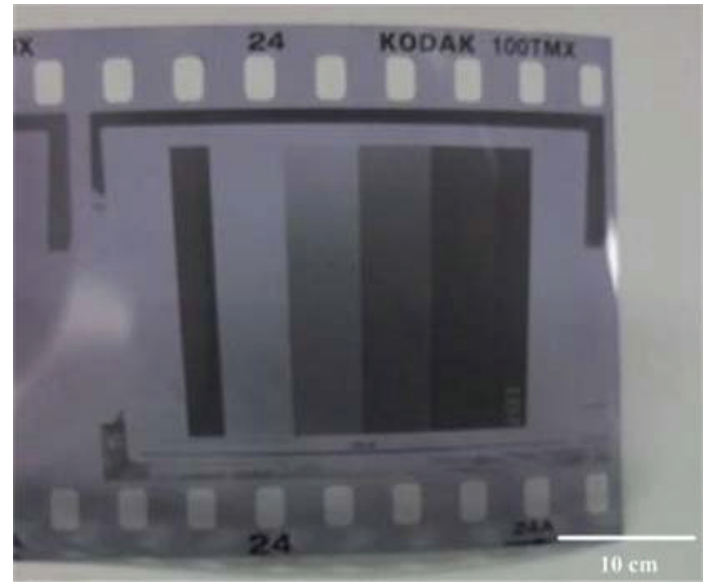

Figure 10: Homemade gray scale mask.

wavelength with gray scale mask, as shown in Figure 11(b). After development, microcolumn array image can be obtained, as shown in Figure 11(c). The microcolumn array was then heated up to $120^{\circ} \mathrm{C}$ to reflow THB-126N to form spherical surface and obtain multistep microlens array mold, as shown in Figure 11(d). The micro-spherical photoresist was sent to sputtered silver film as a seed layer which has the best electrical conductivity. Then, Ni-Co (Nickel cobalt) alloy was electroformed on the seed layer as shown in Figure 11(e). The microlens array structure was transformed into PDMS mold, as shown in Figure 11(f). The mold was released, and PDMS mold with the microlens array structure was formed, as shown in Figure 11(g). Then PDMS with embedded microvoids was molded by PDMS mold, as shown in Figure 11(h). The PDMS mold was released, and the embedded void optical compound film was obtained, as shown in Figure 11(i). Figure 12 shows the gray scale microlens mold after development process.

3.4. Embedded Microvoids PDMS Solvent. The microvoids structure can be embedded in solution by controlling the pressure and rate of air into solution during preparing the PDMS solution, as schematically shown in Figure 13. The embedded microvoids PDMS solvent is as shown in Figure 14.

PDMS with embedded microvoids solvent was poured into molds and the compound optical films with variable size of microlens array were obtained. Figures 15 and 16 are the embedded microvoids optical films with and without the microlens array structure, respectively. By observation, the surface without the microlens array structure seems 


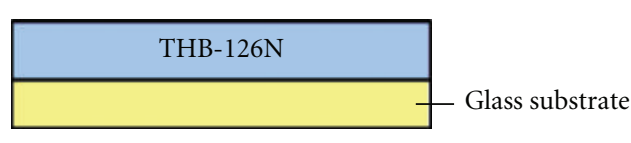

(a) Photoresist coating

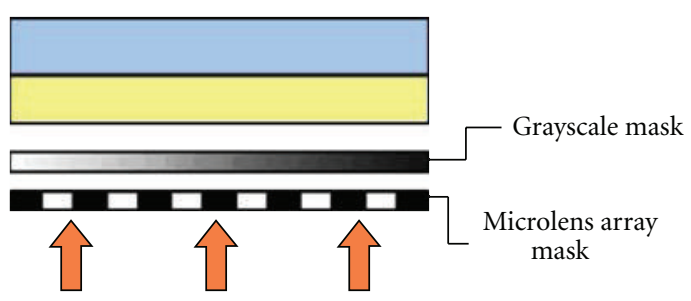

(b) Exposure

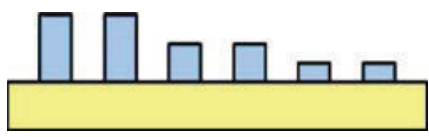

(c) Development

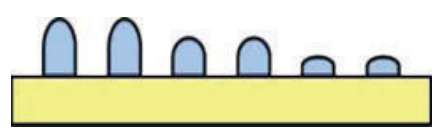

(d) Thermal reflow

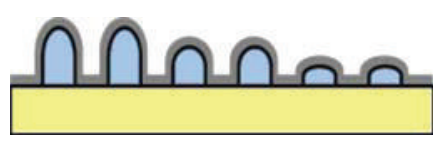

(e) Electroforming

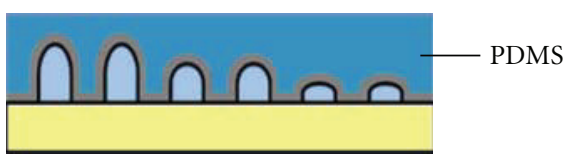

(f) Mould filling

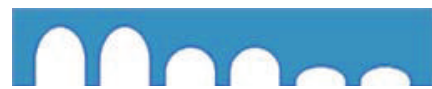

(g) Mould release

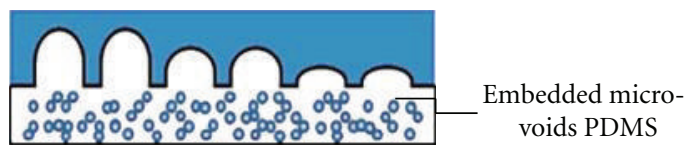

(h) Mould filling

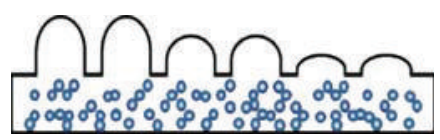

(i) Mould release

FIGURE 11: Manufacturing process of the embedded void optical compound film with gray scale microlens array.

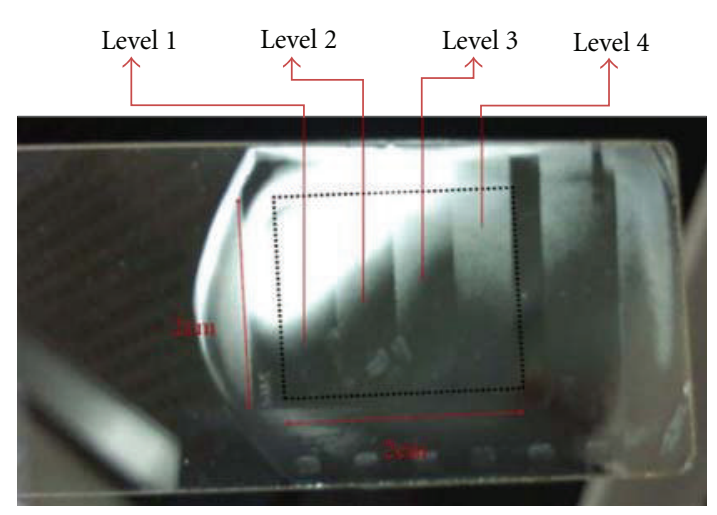

FIGURE 12: Gray scale microlens mold after development.

smoother and more transparent. On contrary, the surface with the microlens array structure seems hazer, which has diffusion effect when it is lighted up.

\section{Results and Discussion}

4.1. Gray Scale Microlens Array Molds. Figures 17 and 18 show the SEM images of each scale of gray scale microlens array mold for no. D40-B and D20-B, respectively. Each scale has different aspect ratios. However, since THB- $126 \mathrm{~N}$ is the negative photoresist, the effect of thermal reflow is not desirable as expected. However, the sizes of each scale are the same as designs.

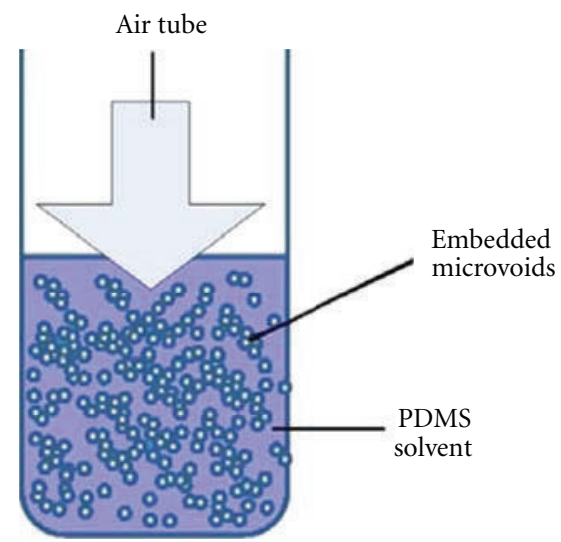

FIGURE 13: Embedded microvoids PDMS polymer solvent.

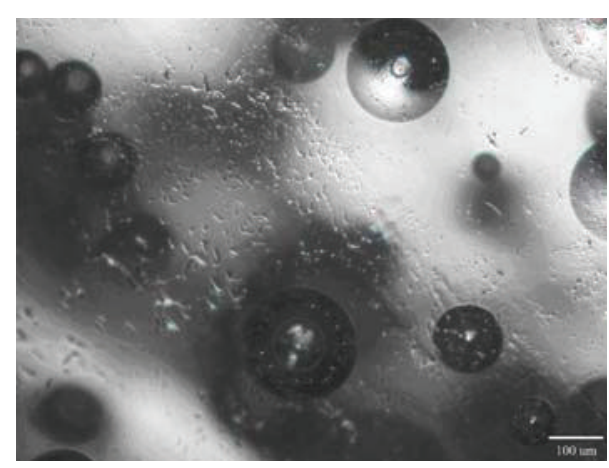

Figure 14: Embedded microvoids OM. 


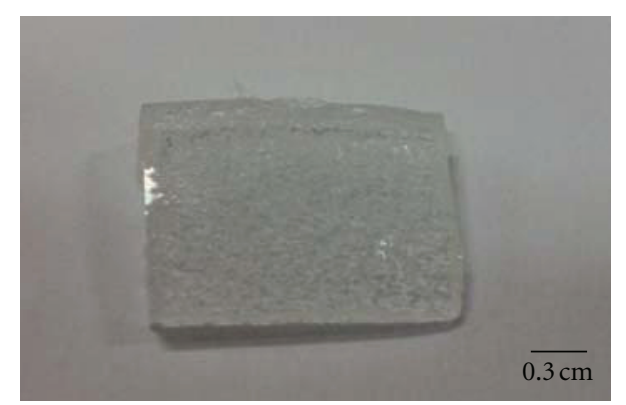

FIGURE 15: Embedded microlens optical film with no lens structure.

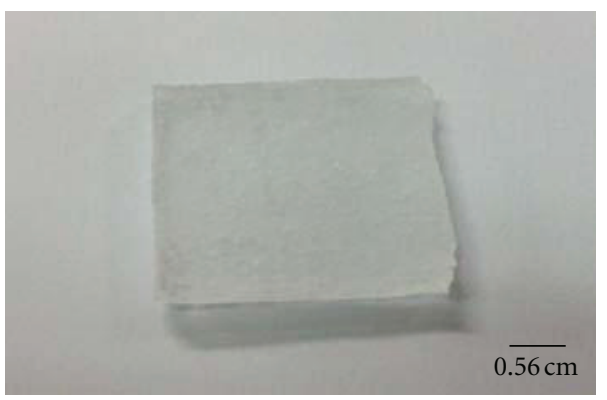

Figure 16: Embedded microvoids film with microlens array structure.

4.2. Soft Lithography. The results of twice molding of the mold by using PDMS and gray scale microlens array are shown in Figures 19 and 20, respectively. After molding, each scale of microlens array has different effect. Besides, in OM images, beneath the microlens array, the black dots are the embedded microvoids structure in the optical film.

4.3. Embedded Microvoids Optical Film. The embedded microvoids optical film was shined by LED light source. In Figure 21, light distribution of embedded microvoids optical film without microlens structure concentrates on the portions close to the source. The light distribution is not uniform. After inserting the reflection layer, the light distribution is more uniform (Figure 22). Regarding the microlens array embedded microvoids optical film, the light distribution is more uniform, and the scattering effect is better than other two cases. Both luminance and uniformity are enhanced as shown Figure 23.

4.4. Optical Measurement Device. The optical characters were measured by Luminance Colorimeter BM-7A, as shown in Figure 24. Nine-spot measurement frequently is used by the industry, as shown in Figure 25.

The embedded microvoids compound optical films with and without microlens array were measured, respectively. The luminance data is listed in Tables 5, 6, and 7, and the average luminance and uniformity values are listed in Table 8 . The result shows that the uniformity of the optical film with microlens array is better than that of the optical film without microlens array. The average luminance and uniformity value of D40-B is higher than that of D20-B
TABLE 5: The average value of luminance of no-lens nine-spot measurement (unit: $\mathrm{cd} / \mathrm{m}^{2}$ ).

\begin{tabular}{lll}
\hline$P 1: 2.64 \times 10^{2}$ & $P 2: 1.90 \times 10^{2}$ & $P 3: 1.18 \times 10^{2}$ \\
$P 4: 5.52 \times 10^{2}$ & $P 5: 2.61 \times 10^{2}$ & $P 6: 1.46 \times 10^{2}$ \\
$P 7: 2.45 \times 10^{2}$ & $P 8: 1.75 \times 10^{2}$ & $P 9: 1.21 \times 10^{2}$ \\
\hline
\end{tabular}

TABLE 6: The average value of luminance of gray scale D40-B's ninespot measurement (Unit: $\mathrm{cd} / \mathrm{m}^{2}$ ).

\begin{tabular}{lll}
\hline$P 1: 2.63 \times 10^{2}$ & $P 2: 1.82 \times 10^{2}$ & $P 3: 1.46 \times 10^{2}$ \\
$P 4: 5.08 \times 10^{2}$ & $P 5: 2.37 \times 10^{2}$ & $P 6: 1.80 \times 10^{2}$ \\
$P 7: 2.71 \times 10^{2}$ & $P 8: 2.12 \times 10^{2}$ & $P 9: 1.69 \times 10^{2}$ \\
\hline
\end{tabular}

TABLE 7: The average value of luminance of gray scale D20-B's ninespot measurement (Unit: $\mathrm{cd} / \mathrm{m}^{2}$ ).

\begin{tabular}{lll}
\hline$P 1: 2.56 \times 10^{2}$ & $P 2: 1.91 \times 10^{2}$ & $P 3: 1.38 \times 10^{2}$ \\
$P 4: 4.71 \times 10^{2}$ & $P 5: 2.42 \times 10^{2}$ & $P 6: 1.49 \times 10^{2}$ \\
$P 7: 2.42 \times 10^{2}$ & $P 8: 1.86 \times 10^{2}$ & $P 9: 1.31 \times 10^{2}$ \\
\hline
\end{tabular}

and the average luminance of the microlens array compound optical film is $4.7 \%$ higher than that of the original optical film without microlens structure. The uniformity of the microlens array compound optical film is $8.4 \%$ higher than the original optical film without lens structure.

4.5. Comparing the Results of Measurement with the Simulated Values. Comparing the experimental with simulation data by $X$-axis contour model, the 4,5 , and 6 points on the $X$-axis of the nine-spot measurement of the experimental data were collected in Table 9, and then the comparison diagrams of the average luminance and average uniformity of the experiment and simulation were drawn. The average luminance data between experiment and simulation are a lot different, as shown Figure 26. But the trend is correct. In addition, the luminance values do not show a lot variation.

The uniformity has been improved greatly, as shown Figure 27. Experimental result shows a close agreement with simulation. It also shows that the uniformity with microlens array structure is better than the optical film without microlens array structure.

\section{Conclusions}

An embedded-voids optical film of variable-sized microlens array which has diffused and light guide capabilities is designed and manufactured in this paper. The results of UV/VIS spectrophotometer show that the transmittance of PDMS can be obtained up to $90 \%$ for the wavelength from $390 \mathrm{~nm}$ to $780 \mathrm{~nm}$. PDMS polymer was used as film material to embed microvoids as diffusion and light guide structure. The design and simulation of gray scale microlens array were carried out by FRED. Two different diameters of $20 \mu \mathrm{m}$ and $40 \mu \mathrm{m}$, and four different heights of microlens array of $5 \mu \mathrm{m}, 15 \mu \mathrm{m}, 25 \mu \mathrm{m}$, and $35 \mu \mathrm{m}$, were selected. A gap between adjacent two microlens is $70 \mu \mathrm{m}$. The result of simulation shows that most light intensity focuses on the film close to 


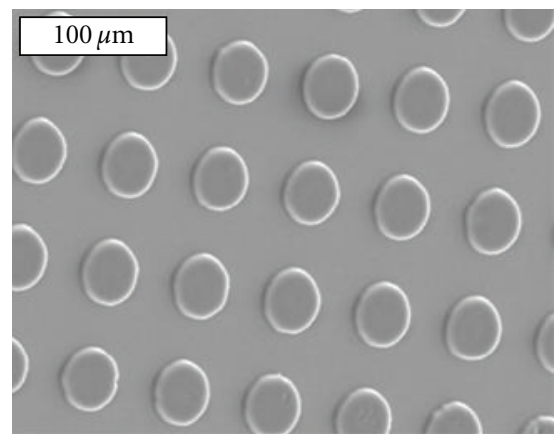

(a)

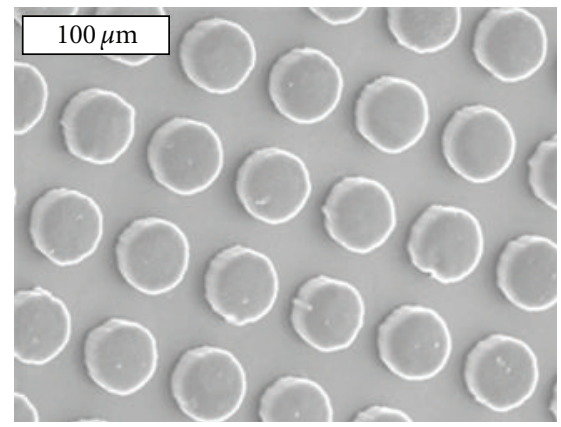

(c)

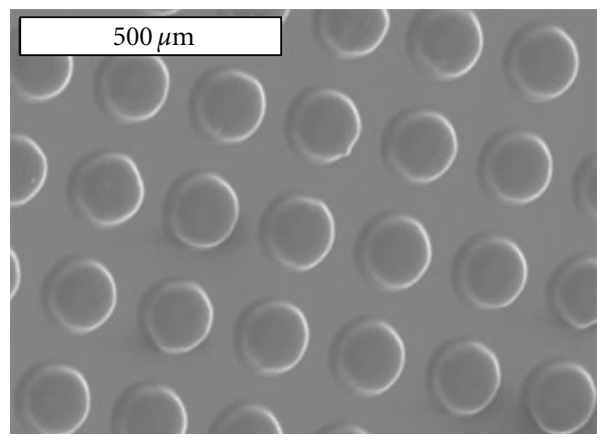

(b)

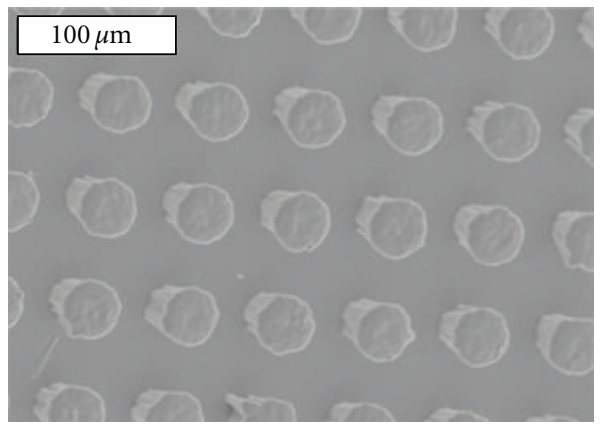

(d)

Figure 17: D40-B SEM image of each scale (a) the first scale ( $34 \mu \mathrm{m})$, (b) the second scale $(23 \mu \mathrm{m}),(\mathrm{c})$ the third scale $(13 \mu \mathrm{m})$, and $(\mathrm{d})$ the forth scale $(6 \mu \mathrm{m})$.

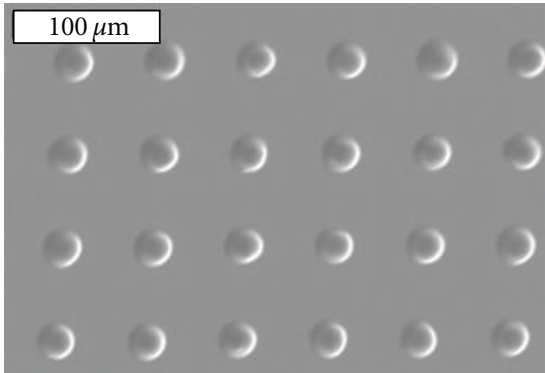

(a)

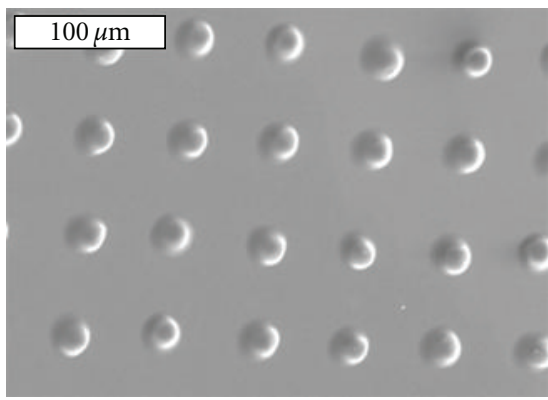

(c)

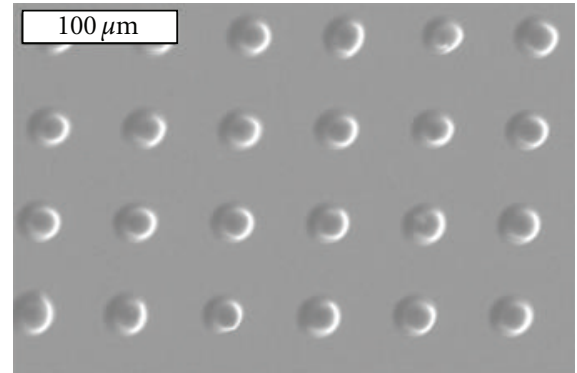

(b)

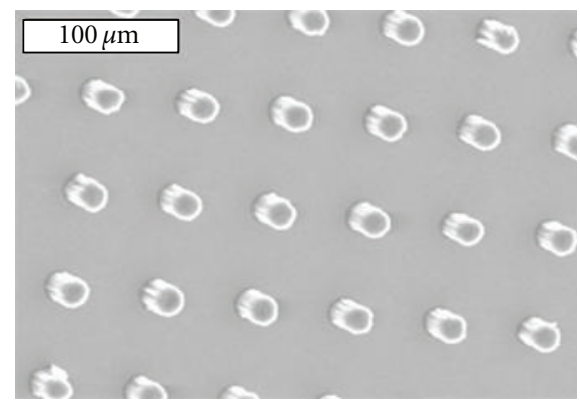

(d)

FIGURE 18: D20-B SEM image of each scale (a) the first scale $(34 \mu \mathrm{m})$, (b) the second scale $(23 \mu \mathrm{m})$, (c) the third scale (13 $\mu \mathrm{m})$, and (d) the forth scale $(6 \mu \mathrm{m})$. 


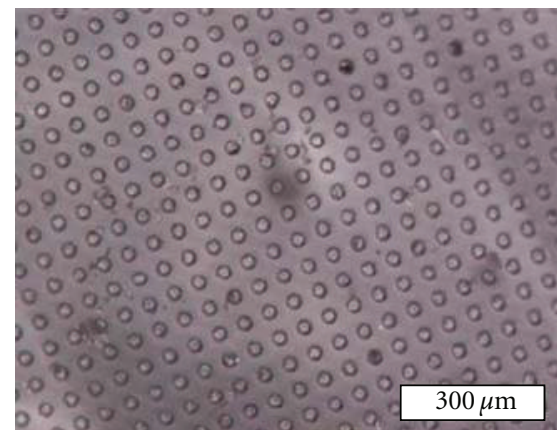

(a)

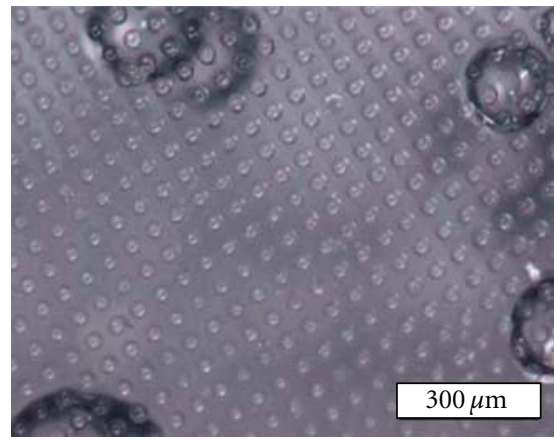

(c)

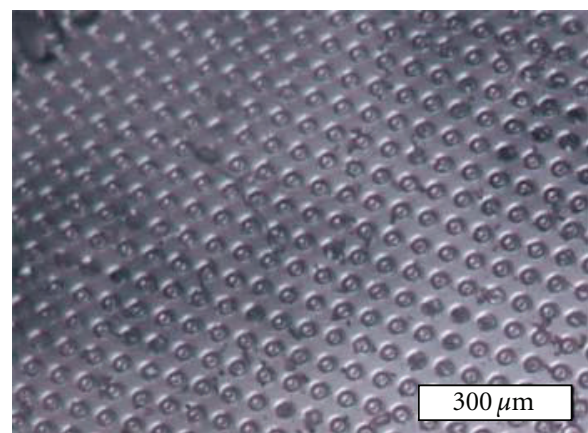

(b)

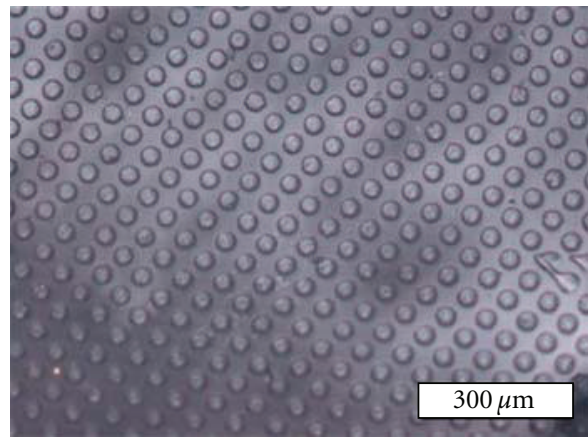

(d)

Figure 19: The PDMS optical film of D40-B microlens array (a) the first scale $(34 \mu \mathrm{m})$, (b) the second scale $(23 \mu \mathrm{m})$, (c) the third scale $(13 \mu \mathrm{m})$, and $(\mathrm{d})$ the forth scale $(6 \mu \mathrm{m})$.

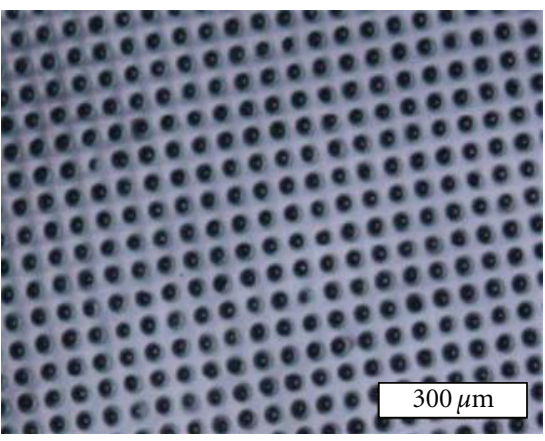

(a)

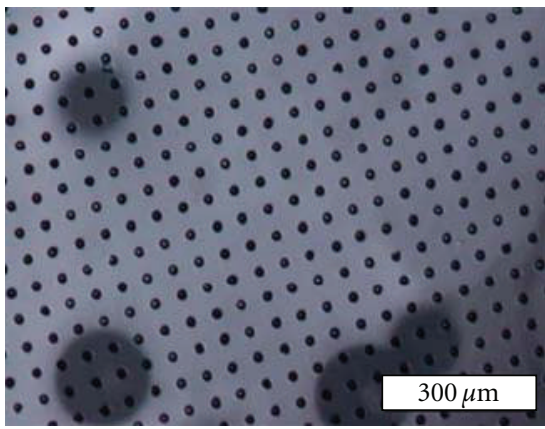

(c)

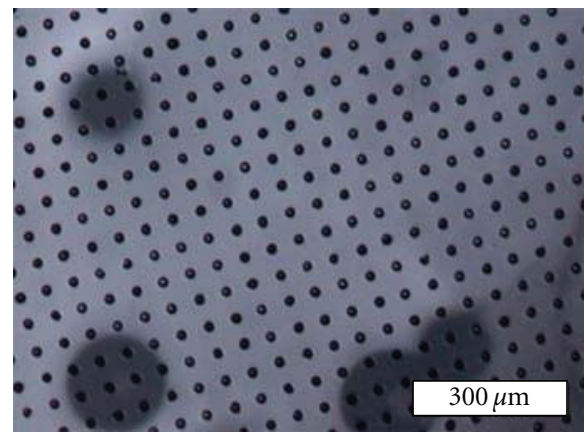

(b)

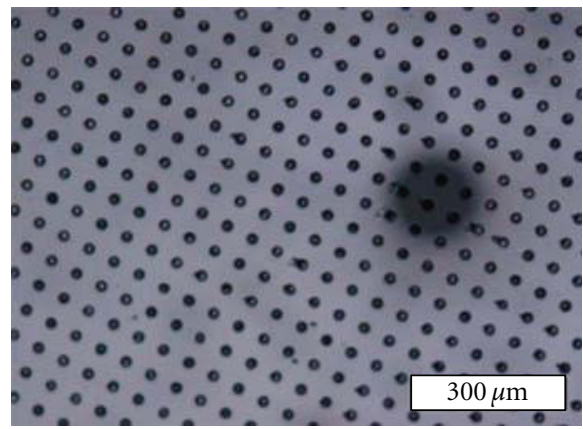

(d)

Figure 20: The PDMS optical film of no. D20-B microlens array (a) the first scale ( $34 \mu \mathrm{m})$, (b) the second scale ( $23 \mu \mathrm{m})$, (c) the third scale $(13 \mu \mathrm{m})$, and (d) the forth scale $(6 \mu \mathrm{m})$. 
TABLE 8: The optical measurement of the average luminance and the average uniformity.

\begin{tabular}{lcccc}
\hline No. & $\begin{array}{c}\text { The average luminance } \\
\left(\mathrm{cd} / \mathrm{m}^{2}\right)\end{array}$ & $\begin{array}{c}\text { The increase/decrease of } \\
\text { the average luminance }\end{array}$ & Uniformity & $\begin{array}{c}\text { The increase/decrease } \\
\text { of the uniformity }\end{array}$ \\
\hline No lens & $2.30 \times 10^{2}$ & - & $21.3 \%$ & - \\
D40-B & $2.41 \times 10^{2}$ & $4.7 \%$ & $29.7 \%$ & $8.4 \%$ \\
D20-B & $2.23 \times 10^{2}$ & $-3.0 \%$ & $27.8 \%$ & $6.5 \%$ \\
\hline
\end{tabular}

TABLe 9: The measurement data of the 4, 5, 6 point of $X$-axis in the experiment.

\begin{tabular}{lccccc}
\hline No. & $P 4\left(\mathrm{~cd} / \mathrm{m}^{2}\right)$ & $P 5\left(\mathrm{~cd} / \mathrm{m}^{2}\right)$ & $P 6\left(\mathrm{~cd} / \mathrm{m}^{2}\right)$ & Average luminance $\left(\mathrm{cd} / \mathrm{m}^{2}\right)$ & Uniformity $\%$ \\
\hline No lens & $5.52 \times 10^{2}$ & $2.61 \times 10^{2}$ & $1.46 \times 10^{2}$ & $3.20 \times 10^{2}$ & $26.5 \%$ \\
D40-B & $5.08 \times 10^{2}$ & $2.37 \times 10^{2}$ & $1.80 \times 10^{2}$ & $3.08 \times 10^{2}$ & $35.4 \%$ \\
D20-B & $4.71 \times 10^{2}$ & $2.42 \times 10^{2}$ & $1.49 \times 10^{2}$ & $2.87 \times 10^{2}$ & $31.6 \%$ \\
\hline
\end{tabular}

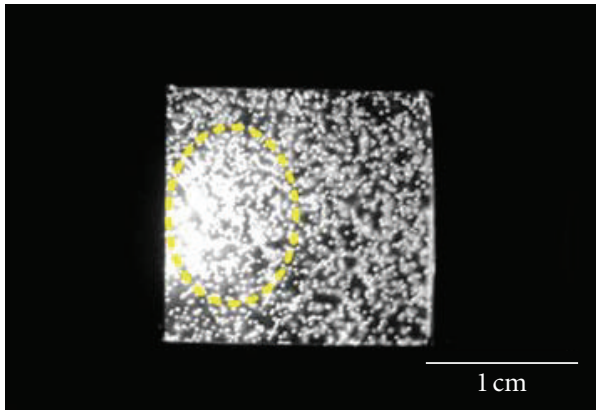

FIGURE 21: Embedded microvoids optical film with no structure.

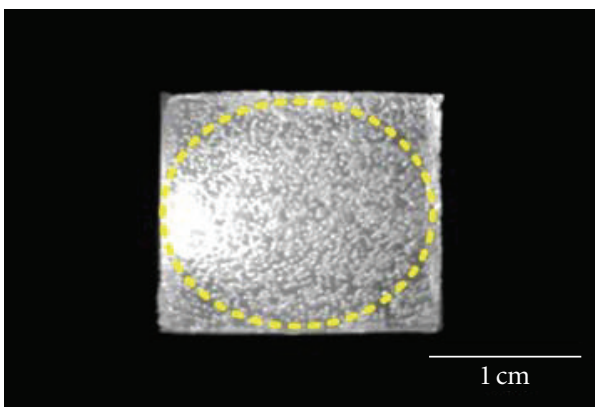

Figure 22: Embedded microvoids optical film with no structure + the reflection film.

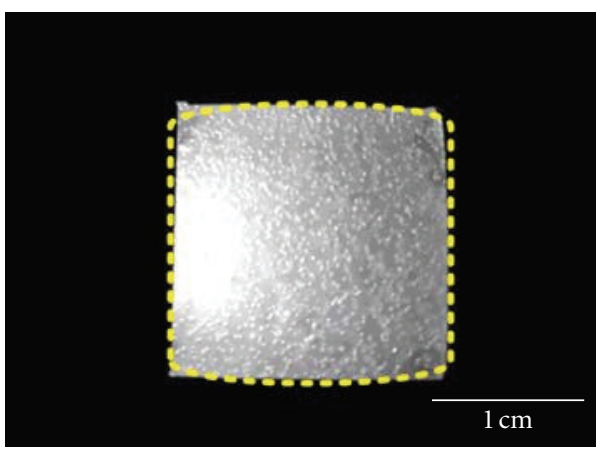

FIGURE 23: Microlens array with embedded microvoids optical film.

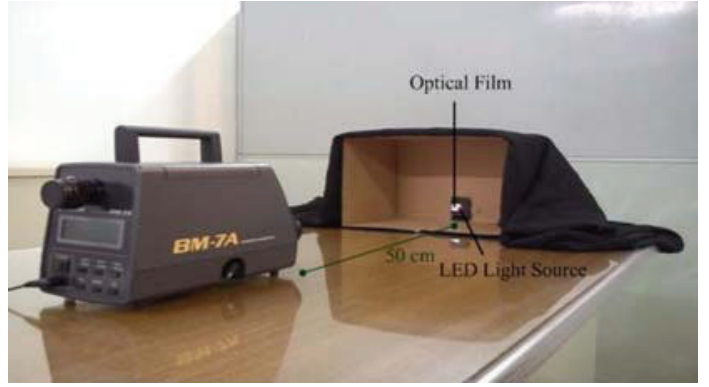

FIGURE 24: Set up of optical measurement.

LED light source
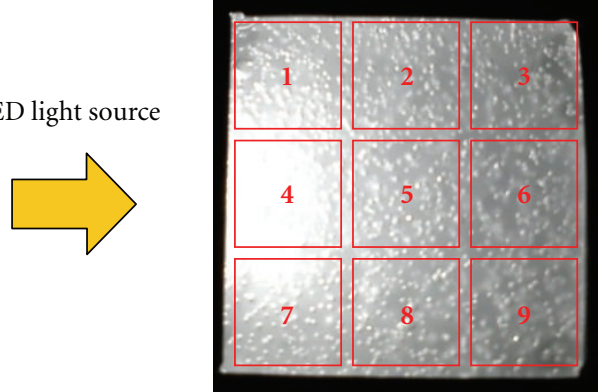

FIGURE 25: Schematic of the nine-spot measurement.

the light source-the average luminance is calculated as 48.5 $\left(\mathrm{cd} / \mathrm{m}^{2}\right)$ and the uniformity is $24.4 \%$. D20-B and D40-B have better uniformity than other two cases, so they were adopted as the parameters to produce compound optical films. According to the measured data, an optical film with variable-sized microlens array can enhance the luminance up to about $5 \%$, and can enhance substantially the uniformity up about $6.5 \%-8.4 \%$. In simulation and experiment, no. D40-B has better gaining effects. The gray scale lithography is utilized to manufacture fourth-levels structure arrays according to the variable-sized microlens array data, and the soft molds of PDMS are utilized to manufacture optical films with variable-sized micro lens array by UV-cured process. 


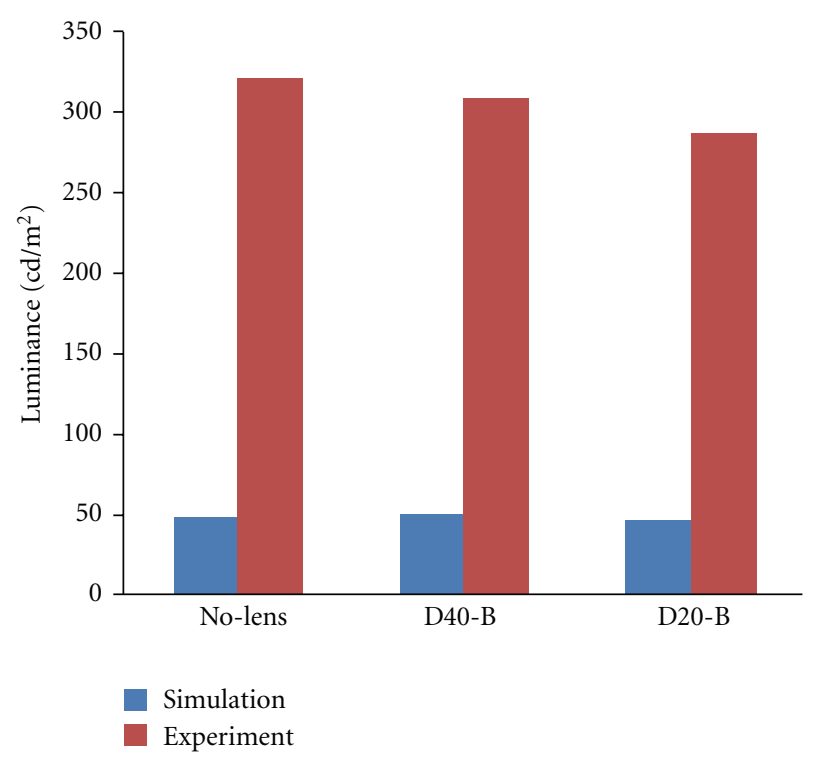

Figure 26: Comparison of the average luminance.

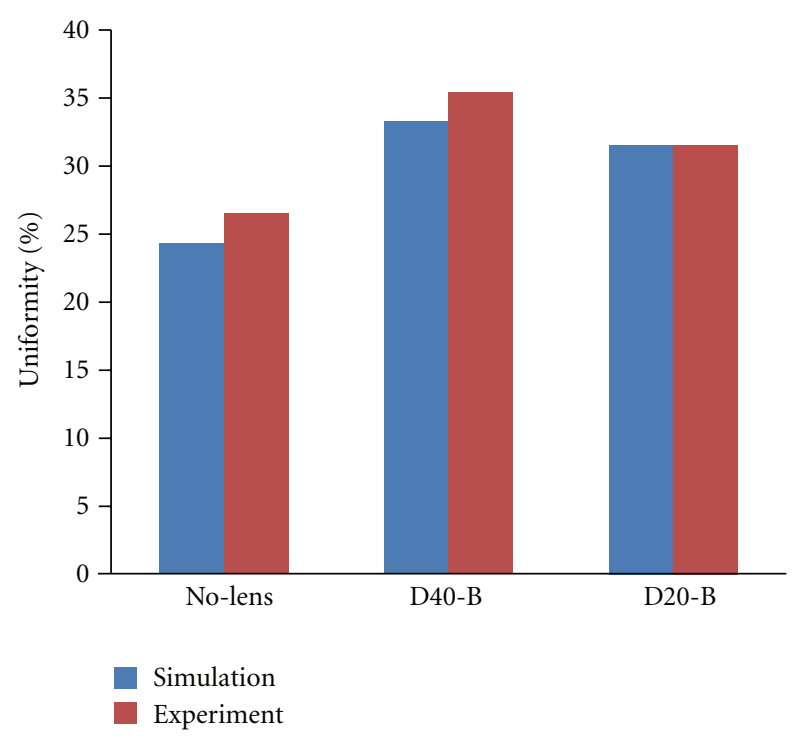

FIgURE 27: Comparison of uniformity.

\section{References}

[1] J. K. Tseng, Y. J. Chen, C. T. Pan, T. T. Wu, and M. H. Chung, "Application of optical film with micro-lens array on a solar concentrator," Solar Energy, vol. 85, no. 9, pp. 2167-2178, 2011.

[2] S. C. Shen, C. T. Pan, K. H. Liu, C. H. Chao, and J. C. Huang, "Fabrication of an eyeball-like spherical micro-lens array using extrusion for optical fiber coupling," Journal of Micromechanics and Microengineering, vol. 19, no. 12, Article ID 125017, 2009.

[3] C. T. Pan, M. F. Chen, P. J. Cheng, Y. M. Hwang, S. D. Tseng, and J. C. Huang, "Fabrication of gapless dual-curvature microlens as a diffuser for a LED package," Sensors and Actuators A, vol. 150, no. 1, pp. 156-167, 2009.

[4] K. H. Liu, M. F. Chen, C. T. Pan, M. Y. Chang, and W. Y. Huang, "Fabrication of various dimensions of high fill-factor micro-lens arrays for OLED package," Sensors and Actuators A, vol. 159, no. 1, pp. 126-134, 2010.

[5] C. T. Pan, Z. H. Liu, and Y. J. Wu, "Embedded dots inside glass for optical film using UV laser of ultrafast laser pulse," Optics and Lasers in Engineering, vol. 49, no. 7, pp. 764-772, 2011.

[6] C. F. Liu, C. T. Pan, K. H. Liu, Y. C. Chen, J. L. Chen, and J. C. Huang, "Optical film for LED with triangular-pyramidal array using size-reducible embossing method," Journal of Materials Engineering and Performance, vol. 20, no. 9, pp. 1544-1553, 2011.

[7] C. T. Pan, Y. C. Chen, M. F. Chen, and Y. C. Hsu, "Fabrication and design of various dimensions of multi-step ashperical microlens arrays for OLED package," Optics Communications, vol. 284, no. 13, pp. 3323-3330, 2011.

[8] C. Tsou and C. Lin, "An improved process for fabricating microlens array with high fill factor and controllable configuration," Journal of Microelectromechanical Systems, vol. 17, no. 4, pp. 1047-1057, 2008.

[9] S. M. Kuo and C. H. Lin, "Non-spherical su-8 microlens array fabricated utilizing a novel stamping process and an electro-static pulling method," in Proceedings of the 22nd IEEE International Conference on Micro Electro Mechanical Systems (MEMS '09), vol. 18, pp. 987-990, January 2009.

[10] L. Mosher, C. M. Waits, B. Morgan, and R. Ghodssi, "Doubleexposure grayscale photolithography," Journal of Microelectromechanical Systems, vol. 18, no. 2, pp. 308-315, 2009.

[11] M. R. Wang and H. Su, "Laser direct-write gray-level mask and one-step etching for diffractive microlens fabrication," Applied Optics, vol. 37, no. 32, pp. 7568-7576, 1998. 

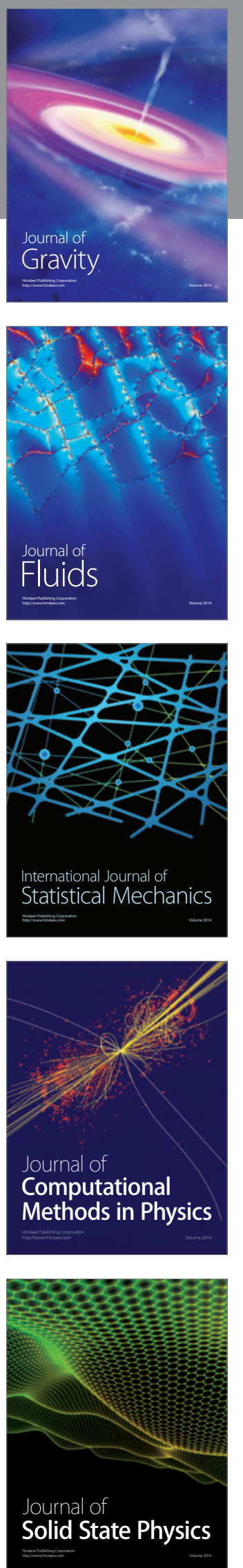

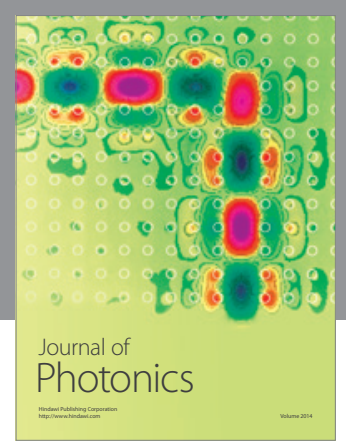

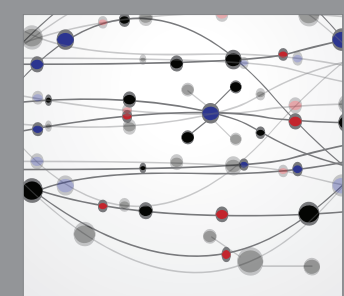

The Scientific World Journal
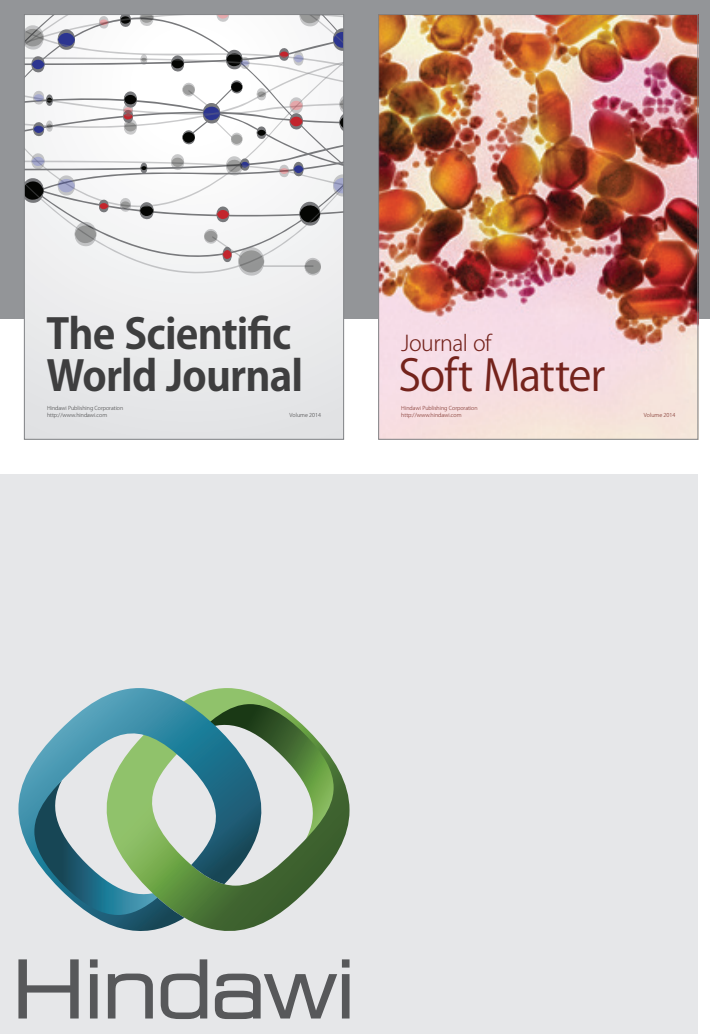

Submit your manuscripts at

http://www.hindawi.com
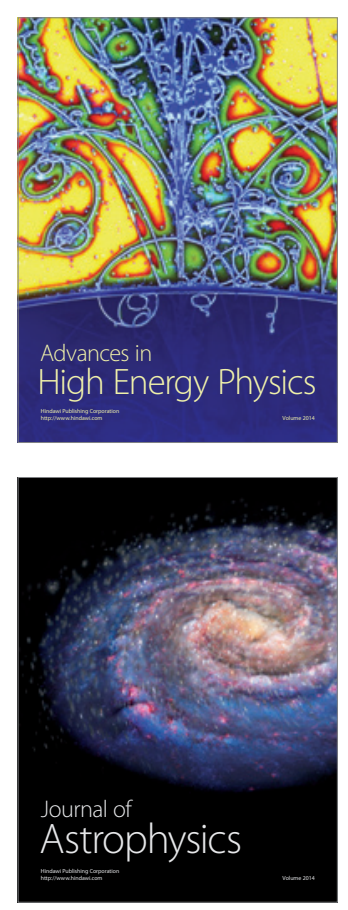
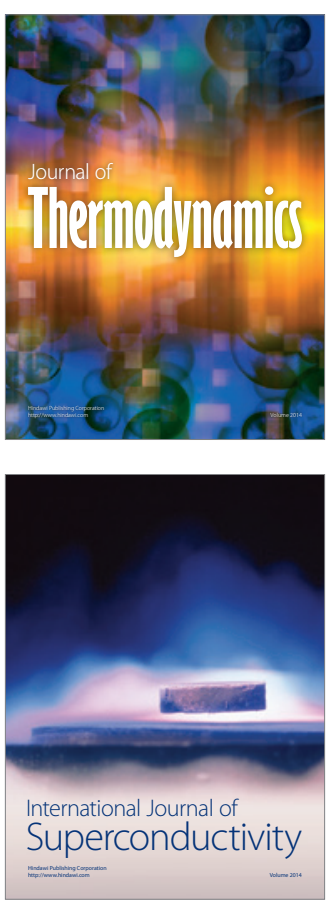
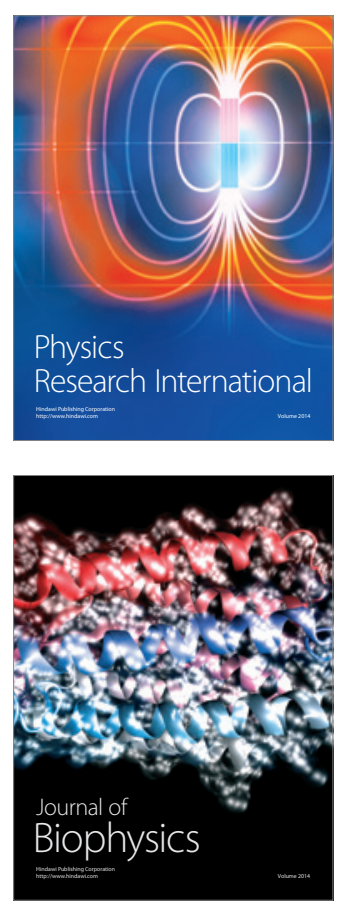
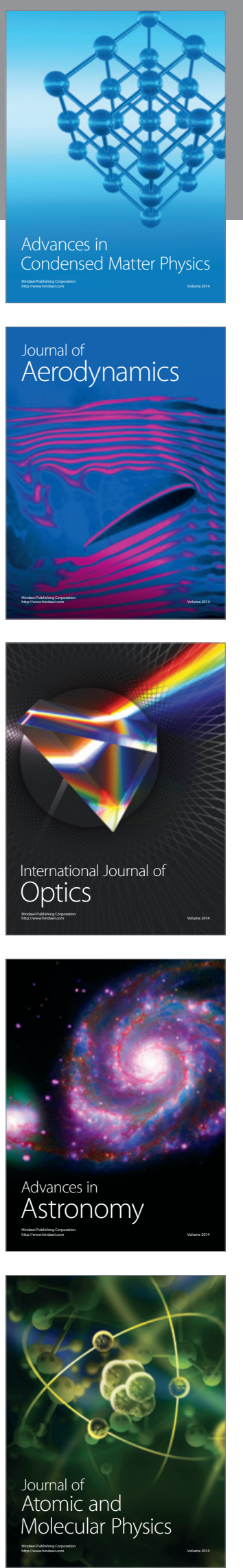